\title{
Secondary Calcinosis of the Foot
}

MAXIME SONDAG, MD; CLÉMENT PRATI, Professor; DANIEL WENDLING, Professor, Rheumatology Department, University Teaching Hospital, Centre Hospitalier Régional Universitaire (CHRU) de Besançon, Besançon, France. Address correspondence to Dr. M. Sondag, CHRU Jean Minjoz, Rheumatology, 3 Boulevard Fleming, Besançon 25030, France. E-mail: msondag@chu-besancon.fr. Ethical approval was not required, according to the policy of the authors' institution. J Rheumatol 2018;45:143-4; doi:10.3899/jrheum.170277

Iatrogenic hypercalcemia with secondary renal chronic failure in hypoparathyroidism has been described ${ }^{1}$, but not with presence of secondary tumoral calcinosis, which rarely occurs in the foot.

A 43-year-old woman presented with a growing swelling of the dorsal side of her right foot that she had had for a few months (Figure 1). The tumefaction was hard and inflammatory without skin injury. Her medical history revealed a thyroidectomy with secondary hypoparathyroidism treated with calcium and vitamin D supplementation for years. Biological investigations found an unknown renal failure associated with hypercalcemia.

Radiograph and then computed tomography (CT) scan of the foot showed amorphous and multilobulated calcifications $(4 \times 4.5 \mathrm{~cm})$ in a periarticular distribution around the base of the third toe, showing a "faveolate" or "cloud-like" aspect (Figure 2) with respect to the cortical bone. The CT scan showed equally hydrocalcic levels formed into lobules (Figure 3). Magnetic resonance imaging showed a mass of the soft parts infiltrating the adjacent muscles, with hyposignal in T1-weighted sequences. After injection of gadolinium, the typical aspect of partitioning of the lesion is observed within this hyposignal zone (Figure 4). Surgical

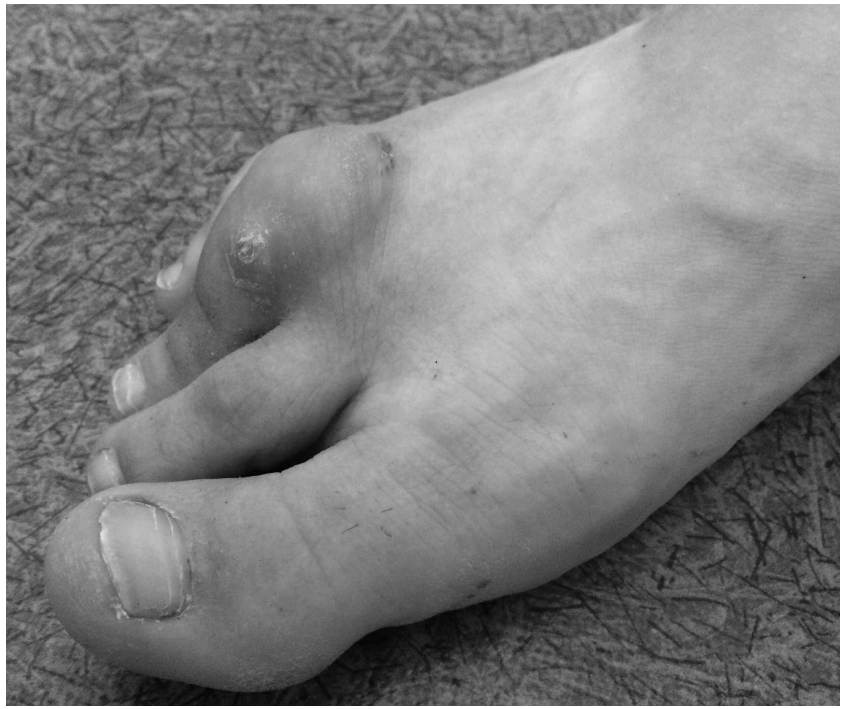

Figure 1. Tumefaction of the foot. excision was performed and pathology analysis was in favor of calcinosis without malignancy.

Cases of iatrogenic hypercalcemia with secondary renal chronic failure in the context of postsurgical hypoparathyroidism have been described ${ }^{1}$, but to our knowledge this is the first case with presence of secondary tumoral calcinosis. Secondary tumoral calcinosis is classically described in systemic sclerosis and in secondary hyperparathyroidism related to chronic renal failure in patients receiving hemodialysis, with the most common locations on hips or shoulders, but rarely on the foot ${ }^{2}$.

\section{REFERENCES}

1. Fritschi BC, Trachsler J, Varga Z, Binet I, Fehr T. Iatrogenic nephrocalcinosis with acute renal failure: an underestimated complication after parathyroidectomy? NDT Plus 2010;3:551-4.

2. Sharkey A, Bibbo C. Tumoral calcinosis of the foot: a radiologic case study. Foot Ankle Spec 2011;4:310-2.

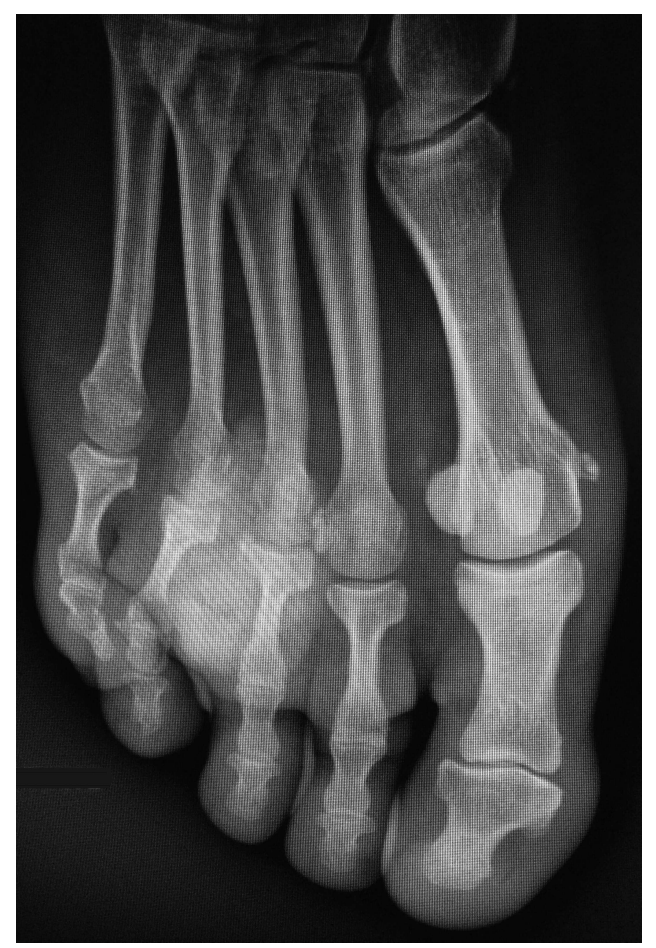

Figure 2. Tumoral calcinosis aspect on radiograph. 


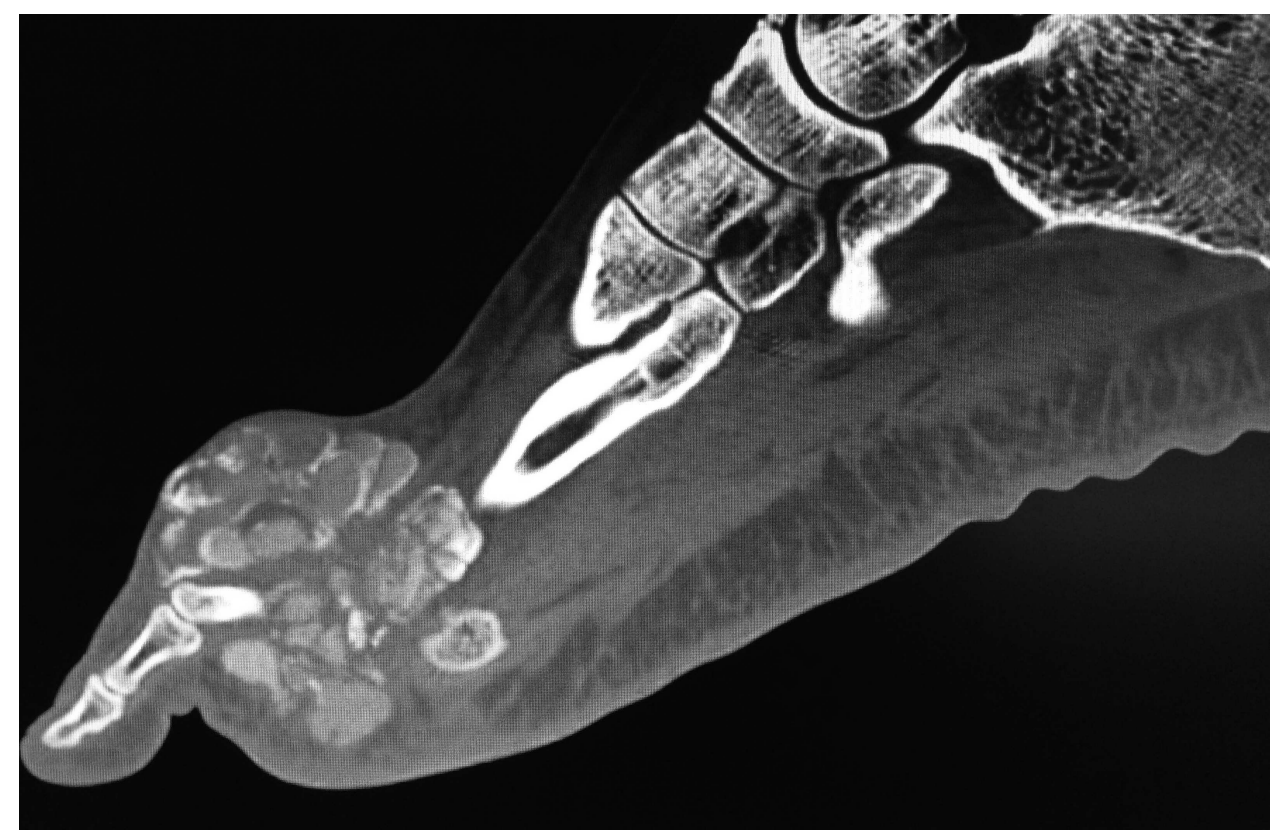

Figure 3. Tumoral calcinosis aspect on computed tomography scan.

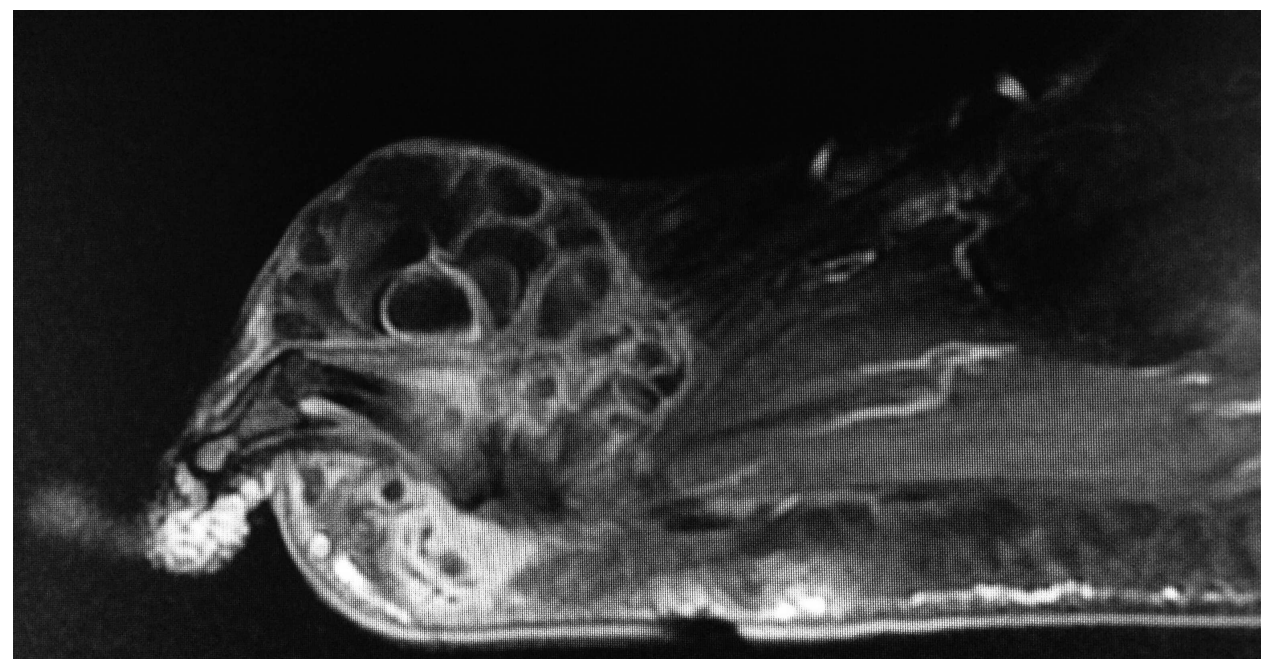

Figure 4. Magnetic resonance imaging aspect (sagittal T1 fat-saturated gadolinium sequence). 